\title{
Finite Element analysis on the stress behavior of Steel Spring and Metal Matrix composite based leaf spring
}

\author{
Harmeet Singh ${ }^{1}$ \\ ${ }^{1}$ Rayat Institute of Engineering and Information Technology
}

May 13, 2020

\begin{abstract}
Aluminum-based metal matrix composite material found to be the best alternative to make auto components with its unique mechanical properties and lightweight. This present work, an attempt has made to use finite element based software to find out stress analysis of steel spring and composite leaf spring. EN 45 steel spring used in automobile vehicles has selected as principle application. For analysis purposes, metal matrix composite based leaf spring prepared and compared with steel leaf spring. The main objective of this research work to find the possibilities to replace the steel spring by metal matrix composite based leaf spring. Finite element based software ANSYS 18.0 was used for analysis purposes. The Result showed that metal matrix composite leaf spring has $38 \%$ less stress as compared to the steel spring. Compared to steel spring, the composite leaf spring has $50 \%$ less weight.
\end{abstract}

\section{Introduction}

The term composite material means a material that is made up of two or more constituent materials. The basic material can be organic, metal or ceramics. The reinforcing material may be in the form of the fibers, particles or flakes. The component of the composite material is separately manufactured as they do not occur naturally and combined mechanically and metallurgical. Composite material with different mechanical and thermal properties when reinforced with a second material, produce a material with different properties from the base and reinforce the material, sometimes superior. The main advantage of the composite material is high stiffness to weight and strength to weight ratio, increase in fatigue strength and improvement in surface smoothness and appearance. The new material can be used with the objective of high strength, lighter and corrosion resistance when compared to traditional materials.

Nanomaterial reinforced in the metal matrix composites based matrix used to find the fatigue life under amplitude cyclic tension fatigue loading whilst controls the surrounding temperature and maximum load was given to the specimen. The S-N curve for three temperatures ranges to determine the effects of high temperature on aluminum and analyze the reason for this cause. [1] The coil springs used in the auto industry and also investigated the fundamental properties of the coil spring by finite element analysis. The coil spring can be designed at higher levels of stress and more than complex stress levels. The materials with a high range of stress and strain come from themselves were the main disadvantage. [2] The jointlife of the suspension system was very important. The servo-hydraulic test facility with a suitable fixture was used to investigate leaf spring joint performance under static and dynamic conditions. [3] The finite element based software to investigate the composite driveshaft. The composite material of the drive shaft was carbon, glass fiber, and epoxy resin. The main objective of the investigation was to enhance the torque and strength of the fiber-reinforced composite shaft. [4] The major issue in the automobile sector is to reduce the weight of the leaf spring and maintain high strength. The steel leaf spring was used in the Maruti 800 car which was taken as a practical application for analysis and optimization of a composite steel mono leaf spring. The three composite materials i.e. E-glass/Epoxy, S-glass/Epoxy, and Carbon/Epoxy were used to 
perform experiments under the same load as performed on a steel spring. [5] The fatigue life of a vehicle suspension system used in the trucks by finite element analysis based software ANSYS under the condition of non-constant amplitude loading. This investigation aimed to find out the non-constant loading used for fatigue life analysis. [6] The stir casting method to produce discontinuous particle reinforced based metal matrix composites material. [7].The finite element analysis used to find the deflection of cantilever beams, properties of the material with a load of transverse at the free end and investigate the displacement response of leaf springs. [8] The different properties of the composite materials for the special requirement so that these materials can be used for applications such as in the aerospace sector, automobile sector (pistons linear, cylinder liners, brakes) and structural components.[9]In automobile industry steel leaf spring material was used in automobile vehicles that can be replaced by lightweight composite material due to light in weight and high strength and the composite materials have properties like good strength and more elastic strain energy. [10]. A composite material means it has two or more material that has better mechanical characteristics than those individual components. Usually, the reinforcing component was distributed in the continuous or matrix component. Metal matrix composite is known as a metal matrix when the matrix was metal.[11] The automobile industry had great interest to make a fuel-efficient vehicle for this industry interested in replacing steel leaf spring other components with composite materials.[12] Finite element analysis based software used to find out the dimension and mechanical properties of composite material. It has observed that for different microstructures and interphase tensile strength, shear strength investigate under different loads by finite element simulations. The finite element based software abacus used for the analysis of mechanical properties, fracture, and failure analysis of the composite material. [13] The composite materials for the requirement and used in a variety of applications such as aerospace, automotive and structural components to save the material, energy, and fuel.[14] CATIA and ANSYS 14.0 were used modeling and finite element analysis. It was concluded that composite material aluminum-silicon carbide was material used for power transmission. [15] The conventional stir casting method to fabricate $11 \mathrm{wt} \%$ boron carbide as reinforced material with aluminum $6061 \mathrm{Al}$ matrix to make new composites material. The whole process to produce composite material was carried out at a temperature of 750@C. [16] ANSYS 12.0 finite element software used for the analysis of leaf spring. In this investigation, a comparative analysis of carbon-epoxy composite leaf spring and steel leaf spring was performed by analytical, finite element analysis software using ANSYS 12. The result of the finite element analysis was compared with experimental results. [17] Four-leaf spring assembly used $n$ light commercial vehicle was the design and analyzed by Ansys 14 software. The CREO software was used for the design and modeling of leaf spring. The finite element result show stresses and deflection verified the existing analytical. The dynamic load experiment of laminated spring also performed using Ansys 14 software. [18] the fabrication of 5,10,15 wt \% of boron carbide reinforced with aluminum alloy LM4 metal matrix composite by using liquid stir casting technique was performed and fabricated under ASTM standard B557M for finding its tensile strength, Hardness and Impact tests were carried out and compared with the base metal and the metallographic structure of its every proportion were characterized by using Scanning Electron Microscope (SEM ) Energy Dispersive X-ray spectroscopy (EDX ) and the combination of B4C and Aluminum alloy LM4 improved its mechanical properties of the base Aluminum alloy.[19] The finite element analysis was also carried out to analyze the connecting rod. The solid works and hyper mesh used to design and meshing of the connecting rod and ANSYS workbench 14.0 software used to analyze purpose. The results showed that the composite material of the connecting rod more suitable than the conventional connecting rod. [20] The static and dynamic analyses were conducted with the help of ANSYS 16 analysis software. The performance results were compared with steel leaf spring. Finally, it was concluded that the composite leaf spring, which was $70 \%$ less in weight, was performing better than conventional steel leaf spring. The modeling software CATIA modeling and for finite element analysis was utilizing ANSYS 16.0 software for Aluminum (Al-B4C). [21].The finite element based software such as CATIA, PRO-Engineer; ANSYS can be used for designing, analyses and shape optimization of composite leaf springs. The study also included the analysis of leaf spring made from composite and its comparison with steel leaf spring. [22]

This paper aims to investigate the stress develop in composite leaf spring and find the possibilities to use it in automobile vehicles in place of steel spring. Metal matrix-based leaf spring has manufactured by the stir casting method. Investigation of stress develop in composite leaf spring is important for the study of fatigue 
strength of leaf spring. According to the Society of automobile India, the stress of leaf spring should be less than $400 \mathrm{MPa}$. If the stress range is more than $400 \mathrm{MPa}$ than it means is the failure of fatigue life of leaf spring. So to know the fatigue life of leaf spring, it is important first to know the stress develop in the leaf spring.

\section{Selection of a practical application}

The EN 45 steel Leaf spring used in automobile utility vehicles has been selected as a practical application for this investigation. The gross weight of the vehicle is $1550 \mathrm{~kg}$ and the Kerb weight of the vehicle is 885 $\mathrm{kg}$. The dimension of steel leaf spring of EN45 is $915 \mathrm{~mm}$ in length, $57 \mathrm{~mm}$ in width and $7 \mathrm{~mm}$ thick as shown in Fig.2.1. and The mechanical properties of EN45 material are given in Table 2.1.

\section{Composite leaf spring}

To manufacture new composite material, $20 \%$ of Boron carbide material used as reinforced material in the Aluminum matrix. Metal Matrix composite based specimen has fabricated by stir casting method. The tensile test and hardness test has performed on the specimen. The result shows that the ultimate tensile strength of new composite material is $595 \mathrm{MPa}$ and hardness is $236 \mathrm{BHN}$. The hardness of composite leaf spring is higher than the EN45 steel spring (185BHN). The tensile strength and hardness of the composite material have confirmed that material is suitable for the manufacturing of leaf spring. Again for manufacture metal matrix composite leaf spring, Aluminum of grade 7075- T651 has taken as base material and $20 \%$ by weight of boron carbide used as reinforcement material. Metal Matrix-based composite leaf spring shown in fig.3.1.

\section{Finite element analysis}

Finite element analysis is a method to solve engineering problems and to predict the behavior of the components in real working. Finite element analysis used in the structural, heat transfer, fluid flow, and mass transport area. To solve any problem, finite element analysis divides the problem into small parts. The finite element analysis based software like ANSYS, NASTRAN, ABACUS, CATIA and SOLID WORKS uses for analysis purposes. The FEA software ANSYS 18.0 has used for stress analysis of steel leaf spring and spring of composite material. The objective of this analysis was to find out the stress development of spring of steel and leaf springs of composite material under a given load and compare the results of spring of steel and composite material based leaf spring. The comparison of the result of leaf spring made from metal matrix composite material with steel leaf spring gives validation to the use of leaf spring of metal matrix composite material in place of traditional steel leaf spring.

\subsection{Geometrical modeling}

The geometrical model of a given dimension, $915 \mathrm{~mm}$ in length, $57 \mathrm{~mm}$ in width and $7 \mathrm{~mm}$ thick of single steel leaf spring was prepared by solid works 17 software. After this geometrical model was imported to the ANSYS software for conducting stress analysis. The geometrical model of steel leaf spring is shown in Fig. 4.1.

After that, the geometric model has imported into ANSYS 18.0. The appropriate material properties of EN45 steel spring were assigned to the geometrical model for analysis purposes

\subsection{The meshing of the steel spring}

After the preparation of the geometrical model and insert material properties, the meshing has performed on the geometrical model of steel leaf spring. Meshing describes the division of parts of the entire model into small elements. The main objective of meshing is to obtain the accuracy of the analysis. The minimum mesh element size of $5 \mathrm{~mm}$ has considered for mesh generation as leaf spring contains sharp edges and curves with the objective of high accuracy. The fine meshing of the geometrical model is shown in Fig.4.2.

\subsection{Boundary conditions}


For the boundary condition, both ends of leaf spring are designed as eye shapes so that both ends are connected to the frame of the vehicle and a simple pin has used to connect leaf spring to the frame so that eye of leaf spring free to rotate but it has restricted to translate and rotate in all other directions. The spring is allowed to move only in x-direction when the load has applied and all other side is restrained to move. As finite element of steel leaf spring has performed by ANSYS software, the load applied at the center of the steel spring in y-direction and stress-induced in the steel spring.

\subsection{Stress Analysis of Steel Leaf Spring}

The Initial load has applied on the spring that was $1000 \mathrm{~N}$. After that $2000 \mathrm{~N}, 3000 \mathrm{~N}, 4000 \mathrm{~N}, 5000 \mathrm{~N}$ and $5400 \mathrm{~N}$ (Full Load) has applied in the spring. The stress values at different loads have shown in Table 4.1.

It was found that maximum stress developed at the outer edge of the steel leaf spring. The stress analysis plot during static analysis of steel leaf spring under different loads is shown in Fig.4.3.

\subsection{Stress Analysis of Composite Leaf Spring}

For the stress analysis of composite leaf, the same procedure has applied on composite leaf spring as applied on steel spring. The result of stress on composite leaf spring has given in Table 4.2. The complete stress analysis of composite leaf spring at different loads is shown in Fig.4.4.

\section{Results and discussion}

The finite element analysis has performed to know the stress behavior of steel spring and composite leaf spring. During the analysis, the range of load is applied from $1000 \mathrm{~N}$ to $5400 \mathrm{~N}$ on spring and results of stress are described in Table 5.1.

By compared the result of the stress of steel spring and composite leaf spring material, it has observed that composite leaf spring has $38 \%$ less stress as compared to the steel spring as shown in fig. 5..It means that fatigue life composite leaf spring is more than steel spring. According to the Society of Automobile Engineering (SAE)[23] and Indian standard 1135 (1995)[24] recommends that fatigue strength of leaf spring should be more than 100000 cycles and less than $400 \mathrm{MPa}$. A fatigue life over 100000 cycles assures that road life of the spring will be more than $160000 \mathrm{~km}$ on the highway. The off-road running may reduce the life of the spring. So Finite element analysis shows that the stress range is very less than stress limit.

\section{Conclusion}

The present finite element analysis was carried out to find the possibilities to use of laminated spring made from metal matrix based composite material in an automobile. The laminated spring used in automobile vehicles was taken as a research application. The metal matrix based composite laminated spring was manufactured by the stir casting method.FEA based ANSYS 18.0 software was used to find develop stress and service life of laminated spring of steel and metal matrix based composite material. Based on the finite element analysis execute on spring of steel and laminated spring of composite material, the following conclusions have drawn:-

- The laminated spring of metal matrix composite was successfully developed by the finite element method to obtain the design of a new laminated spring of metal matrix composite with low weight and almost the same properties.

- The single laminated spring of composite material is lighter in weight than the steel laminated spring

- FEA based software ANSYS 18.0was successfully used to find stress developed and service life of laminated spring made of steel and metal matrix based composite material.

- The life cycle of spring of steel and spring of composite was more than the design value 100000 cycles.

\section{References}


1. Leong, I. K. (2008), "Aluminium 7075-T6 Cyclic Fatigue Testing at Elevated Temperatures", Ph.D. Thesis, University of New South Wales, Australia.

2. Prawoto, Y., Ikeda, M., Manville, S. K. and Nishikawa, A. (2008), "Design and Failure Modes of Automotive Suspension Springs", Engineering Failure Analysis, vol. 15, pp. 1155-1174.

3. Subramanian, C. and Senthilvelan, S. (2010), "Effect of Reinforced Fiber Length on the Joint Performance of Thermoplastic Leaf Spring", Materials and Design, vol. 31,pp.3733-3741.

4. Talib, A. R. A., Ali, A., Goudah, G., Lah, N. A. C., and Golestaneh, A. F.(2010), "Developing a Composite Based Elliptic Spring for Automotive Application", Materials and Design, vol. 31, pp.475484.

5. Raghavedra, M., Hussain, S. A., Pandurangadu, V. and Palani, K. (2012), "Modeling and Analysis of Laminated Composite Leaf Spring under the Static Load Condition by using FEA, "International Journal of Modern Engineering Research, vol.1, Iss. 4, pp. 1875-1879.

6. Karthik, J. P., Chaitanya, K. L. and Sasanka, C. T. (2012), "Fatigue Life Prediction of a Parabolic Spring under Non-constant Amplitude Proportional Loading using Finite Element Method", International Journal of Advanced Science and Technology, vol. 4,pp.143-158.

7. Sozhamannan, G. G., Balasivanandha, S. and Venkatagalapathy, V.S. K. (2012), "Effect of Processing Parameters on Metal Matrix Composites: Stir Casting Process", Journal of Surface Engineered Materials and Advanced Technology, vol. 2, pp. 11-15.

8. Roy, D. K., and Saha, K. S.(2013), "Nonlinear Analysis of Leaf Springs of Functionally Graded Materials", Procedia Engineering, vol. 51, pp.538-543.

9. Suresh, S. and Moorthi, N. S. V. (2013), "Process Development in Stir Casting and Investigation on Microstructures and Wear Behavior of $\mathrm{TiB}_{2}$ on Al6061 MMC", Procedia Engineering, vol. 64, pp. 1183-1190.

10. Satpute, A. A. and Chavan, S.S. (2013), "Mono Composite Leaf Spring - Design and Testing", Indian Journal of Applied Science, vol. 3, Iss. 7,pp.282-285.

11. Kumar, A., Lal, S. and Kumar, S.(2013), "Fabrication and Characterization of $\mathrm{A} 359 / \mathrm{Al}_{2} \mathrm{O}_{3} \mathrm{Metal}$ Matrix Composite using Electromagnetic Stir Casting Method", Journal of Material Research and Technology, vol. 2, Iss. 3, pp. 250-254.

12. .Ghodake, A. P. and Patil, K.N.(2013), "Analysis of Steel and Composite Leaf Spring for Vehicle", Journal of Mechanical and Civil Engineering, vol. 5, Iss. 4, pp.68-76.

13. Qing, H. (2013), "2D Micromechanical Analysis of SiC/Al Metal Matrix Composites under Tensile, Shear and Combined Tensile/Shear Loads", Materials and Design, vol. 51, pp. 438-447.

14. Pawar, P. B., and Abhay, A. U. (2014), "Development of Aluminium Based Silicon Carbide Particulate Metal Matrix Composite for Spur Gear, Procedia Materials Science, vol. 6, pp. 1150-1156.

15. Auradi, V., Rajesh, G.L. and Kori, S. A. (2014), "Processing of $\mathrm{B}_{4} \mathrm{C}$ Particulate Reinforced 
6061Aluminum Matrix Composites by Melt Stirring Involving Two-step Addition", Proceedings of $3^{\text {rd }}$ International Conference on Materials Processing and Characterization, Gokaraju Rangaraju Institute of Engineering and Technology, pp.1068-1076.

16. Ravindra, P. and Belkar, S. (2014), "Performance Analysis of Carbon Fiber with Epoxy Resin-based Composite Leaf Spring", International Journal of Current Engineering and Technology, vol. 4, pp.536541.

17. Mistry, R.(2014), "Dynamic Analysis of A Leaf Spring", International Journal of Research in Engineering and Advanced Technology, vol. 2, Iss. 2, pp.2320-8791.

18. .Stalin, B. and Murugan, C. (2016), "Evaluation of Mechanical Behavior of Aluminium Alloy Boron Carbide MMC", International Journal of Seventh Sense Research Group, vol.4, pp.32-36.

19. Ramasubramanian, S., Chandrasekaran, M., Sridhar, R. and Karunakaran, K. (2017), "Design, Manufacture, and Analysis of $\mathrm{Al} / \mathrm{SiC} \mathrm{MMCs}$ for Connecting Rod", IOP Conference Series: Materials Science and Engineering.

20. Shukoor, S. A. and Rao, A. A. (2017), "Fabrication, Design Optimization, and Stress Analysis of Mono Leaf Spring Using Metal-Matrix Composites", International Journal of Innovative Technology and Research, vol.5, pp. 6073-6077.

21. Elatharasan, G. and Krishnaraj, S. (2017), "Fatigue Behavior of Aluminium Reinforced Metal Matrix Composite", Advances in Natural and Applied Sciences, vol.11, pp. 31-36.

22. Kumar, A., and Rao, M. C. V. (2018), "Design, Manufacture, and Analysis of Al/SiC MMCs for Connecting Rod", Materials Today: Proceedings, vol. 5, pp. 5716-5721.

23. IS 1135.1995: Springs- Leaf Springs Assembly for Automobiles.

24. Spring Design Manual. Design and Application of Leaf Springs, AE-11, Society of Automotive Engineer, HS-788, 1990. 
Finite Element analysis on the stress behavior of Steel Spring and Metal Matrix composite based leaf spring

Photos

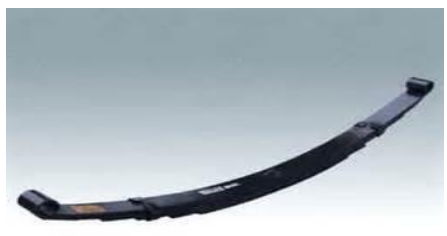

Fig. 2.1: EN45 Steel Leaf Spring

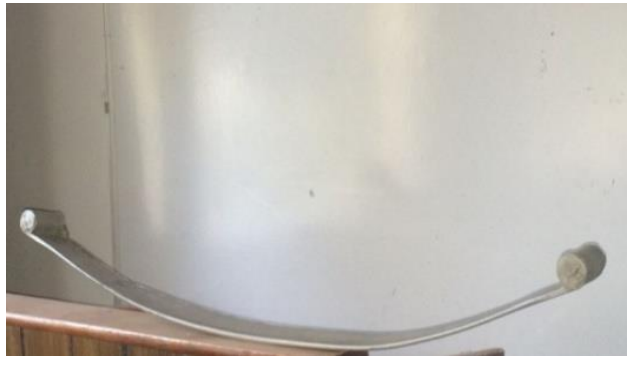

Fig.3.1: Composite Leaf Spring 
Finite Element analysis on the stress behavior of Steel Spring and Metal Matrix composite based leaf spring

\begin{tabular}{|l|l|l|l|l|l|l|}
\multicolumn{8}{c|}{ Table 2.1 Mechanical Characteristics of EN 45 Steel Spring } \\
\hline Properties & $\begin{array}{l}\text { Young's } \\
\begin{array}{l}\text { Modulus, } \\
\left(\mathrm{N} / \mathrm{mm}^{2}\right)\end{array}\end{array}$ & $\begin{array}{l}\text { Poisons } \\
\text { Ratio }\end{array}$ & $\begin{array}{l}\text { Tensile } \\
\text { Strength } \\
(\mathrm{MPa})\end{array}$ & $\begin{array}{l}\text { Density } \\
\left(\mathrm{kg} / \mathrm{m}^{3}\right)\end{array}$ & $\begin{array}{l}\text { Hardness } \\
(\mathrm{BHN})\end{array}$ \\
\hline $\begin{array}{l}\text { Material } \\
\text { EN45 }\end{array}$ & 204000 & 0.30 & 621 & 7850 & 185 \\
\hline
\end{tabular}

Table 4.1. Stress in Steel Leaf Spring at Different Loads

\begin{tabular}{|c|c|}
\hline Load Applied (N) & Stress in Steel Spring (MPa) \\
\hline 1000 & 85.90 \\
\hline 2000 & 122.46 \\
\hline 3000 & 150.56 \\
\hline 4000 & 174.58 \\
\hline 5000 & 195.98 \\
\hline 5400 & 204.01 \\
\hline
\end{tabular}

Table 42. Stress in Composite Leaf Spring under Different Load

\begin{tabular}{|c|c|}
\hline Load Applied (N) & Stress in Composite Leaf Spring (MPa) \\
\hline 1000 & 51.75 \\
\hline 2000 & 74.20 \\
\hline 3000 & 91.93 \\
\hline 4000 & 107.30 \\
\hline 5000 & 120.91 \\
\hline 5400 & 126.11 \\
\hline
\end{tabular}

Table5.1: Result of stress

\begin{tabular}{|c|c|c|}
\hline Load Applied (N) & $\begin{array}{c}\text { Stress in Steel Spring } \\
\text { (MPa) }\end{array}$ & $\begin{array}{c}\text { Stress in Composite Spring } \\
\text { (MPa) }\end{array}$ \\
\hline 1000 & 85.9 & 51.75 \\
\hline 2000 & 122.40 & 74.20 \\
\hline 3000 & 150.50 & 91.02 \\
\hline 4000 & 174.58 & 107.30 \\
\hline 5000 & 195.98 & 120.91 \\
\hline 5400 & 204.01 & 126.11 \\
\hline
\end{tabular}

